\title{
Design para projetos de Humanidades Digitais
}

\author{
Design for Digital Humanities Projects
}

PORTUGAL, Cristina; Doutora; Royal College of Art

crisportugal@gmail.com

\begin{abstract}
Resumo
Este artigo apresenta um projeto de pesquisa intitulado, "Design * Tecnologia": design contemporâneo em ambientes digitais. O projeto é composto por uma série de livros que trazem de forma didática os conceitos básicos, estudos e conteúdos de referência sobre Design e suas relações com a Tecnologia e outras áreas afins. Conceitos que podem servir de base para projetos de Humanidades Digitais. Ao considerar que projetos de Humanidades Digitais envolvem designers que estão preocupados com a representação simbólica da linguagem. O design, como produtor das linguagens contemporâneas - entre elas a hipermídia e a transmídia -, tem um papel ativo e determinante na sociedade onde atua, como um dos principais edificadores da cultura. Fazer aflorar, de forma inequívoca, a percepção e a conscientização deste papel do design é um dos objetivos principais deste projeto de pesquisa.
\end{abstract}

Palavras Chave: design; tecnologia; interdisciplinaridade.

\begin{abstract}
This article presents a research project entitled, "Design * Technology": contemporary design in digital environments. The project is composed by a series of books that bring, didactically, the basic concepts, studies and reference contents about Design and its relationships with Technologies and other common areas. Concepts that can serve as a basis for Digital Humanities projects. Considering that Digital Humanities projects involve designers who are concerned with the symbolic representation of language. Design, as producer of contemporaneous languages - among them the hypermedia and the transmedia - has an active and determinant role in the society where it acts, as one of the main builders of culture. To make flourish, unequivocally, the perception and awareness about this role of design is one of the main objectives of this research project.
\end{abstract}

Keywords: design; technology; interdisciplinarity 


\section{Introdução}

O presente artigo apresenta um projeto de pesquisa intitulado "Design * Tecnologia: Design contemporâneo em ambientes digitais", que nasceu durante o estágio de pósdoutoramento de Cristina Portugal, realizado na School of Communication da Royal College of Art (RCA) em Londres. O projeto é composto por uma série de livros que trazem de forma didática os conceitos básicos, estudos e conteúdos de referência sobre Design e suas relações com a Tecnologia e outras áreas afins.

Trata-se de um desdobramento do trabalho de pesquisa realizado em 2013 que resultou no livro Design, Educação e Tecnologia, publicado em duas versões: no formato de livro impresso e de livro digital hipermidiático (design-educacao-tecnologia.com). O livro disponibiliza conceitos teóricos e estéticos de design para ambientes digitais.

Em 2017, o livro digital Design, Educação e Tecnologia passou por revisão e redesign para, em sua $2 \%$ edição, se tornar o primeiro livro a integrar a série de Design * Tecnologia. $O$ segundo livro, intitulado Design, Comunicação e Tecnologia, encontra-se em desenvolvimento com previsão de lançamento para final de 2018.

Neste artigo será apresentado mais especificamente o segundo livro "Design, Comunicação e Tecnologia", cujo conteúdo seguirá a mesma estratégia de produção do primeiro, ou seja, o próprio processo de construção do livro consistirá na aplicação dos conceitos de design de hipermídia, possibilitando transformar o conteúdo teórico do livro em prática. A apresentação de informação é feita de maneira multilinear, como hipertexto, e estruturada em nós semânticos ligados entre si (em rede), que oferecem alternativas para a navegação.

O conteúdo que será apresentado no novo livro tem por tema a reflexão e discussão sobre o papel do design no complexo contexto do ambiente das mídias. Para McLuran e McLuran (1988), tal ambiente, denominado por eles de "ecologia das mídias", engloba tecnologias de informação e comunicação e as comunidades culturais em que elas se originam e se desenvolvem. Engloba, também, protocolos, práticas, produtos e instituições envolvidos na criação e divulgação destas mídias. Tais reflexões e discussões são importantes e necessárias para que se compreenda a responsabilidade social dos designers como produtores e criadores de sistemas de informação e de comunicação bem como, de padrões estéticos, que irão, certamente, ter influência na cultura e na estrutura da sociedade.

A pesquisa tem por objetivo geral fomentar o exercício da reflexão, do debate e da crítica, proporcionando ao profissional uma visão abrangente das características e possibilidades de interrelação do design, da comunicação e da tecnologia com foco nas linguagens hipermidiáticas possibilitadas pelas tecnologias de informação e comunicação.

A presente investigação tem um viés qualitativo e será desenvolvida nos moldes de uma pesquisa exploratória, em consonância com outras fontes que darão base ao tema abordado, como pesquisa bibliográfica e documental, leitura e análise de textos, entre outras técnicas.

Como resultado este estudo disponibilizará uma série de livros que poderão contribuir com discussões sobre conceitos de Design e Tecnologia. Diante da presença cada vez mais constante das Tecnologias de Informação e Comunicação em todos os âmbitos da sociedade, o campo de atuação dos estudiosos das ciências ligados ao Design, à Comunicação e à Tecnologia e seus efeitos na sociedade tornam-se cada vez mais interdisciplinares. Neste artigo contemplaremos 
questões relacionadas ao Design e às práticas de "Humanidades Digitais". Tendo por base, alguns autores como: Anne Burdick et al. (2012), Johanna Drucker (2014), Jentery Sayers (2018), dentre outros que trazem reflexões sobre o quanto o design é vital às práticas em "Humanidades Digitais".

\section{Por que este projeto}

O Manifesto de Humanidades Digitais foi criado em 2010, na cidade de Paris durante a realização do THATCamp. Estabeleceu-se a seguinte definição para "Humanidades Digitais":

1. A opção da sociedade pelo digital altera e questiona as condições de produção e divulgação dos conhecimentos.

2. Para nós, as humanidades digitais referem-se ao conjunto das Ciências humanas e sociais, às Artes e às Letras. As humanas digitais não negam o passado, apoiam-se, pelo contrário, no conjunto dos paradigmas, savoir-faire e conhecimentos próprios dessas disciplinas, mobilizando simultaneamente os instrumentos e as perspectivas singulares do mundo digital.

3. As humanidades digitais designam uma transdisciplina, portadora dos métodos, dos dispositivos e das perspectivas heurísticas ligadas ao digital no domínio das Ciências humanas e sociais. (DACOS, 2011 p.1)

O Design pode colaborar para projetos em Humanidades Digitais, pois o campo do Design engloba o conjunto de pesquisas e experiências que visam facilitar a utilização dos recursos digitais no âmbito social, tornando-os mais intuitivos e acessíveis. Neste artigo não se tem a pretensão de discutir o campo das Humanidades Digitais, mas sim, refletir sobre a relevância de conceitos de Design às práticas em "Humanidades Digitais". Pois segundo a definição para humanidades digitais encontrada no dicionário de termos literários e teoria literária de Cuddon (2013) Humanidades Digitais é um amplo campo e envolve diversas disciplinas.

Um amplo campo multidisciplinar dedicado a entender a intersecção entre a tecnologia da informação e as humanidades tradicionais. As áreas cobertas incluem a digitalização de textos e o uso de computadores como ferramentas para linguística e análise de texto, apesar de que seu escopo em potencial é considerado mais vasto entre seus praticantes. (CUDDON, 2013, p.204)

Para tanto, faz-se necessário pesquisas com caráter interdisciplinar entre ciências de Design, Humanas, Sociais e Tecnologia da Informação e Comunicação, proposta do projeto de pesquisa Design * Tecnologia, objeto deste estudo. Assim, com este estudo pretende-se colaborar com o campo emergente das "Humanidades Digitais" que apresenta um crescimento de centros de pesquisa, associações, publicações, eventos científicos nacionais e internacionais associados às práticas humanistas.

Em relação ao Design e às práticas em "Humanidades Digitais", alguns autores como Anne Burdick et al. (2012), Johanna Drucker (2014), Jentery Sayers (2018), dentre outros trazem reflexões em seus trabalhos sobre o quanto o design é vital às práticas em "Humanidades Digitais". Destaco Burdick et al. (2012), ao afirmar que, para os humanistas digitais, o Design é uma prática criativa que aproveita restrições culturais, sociais, econômicas e tecnológicas para trazer sistemas e objetos para o mundo. $O$ design em diálogo com a pesquisa é simplesmente uma técnica, mas quando usado para representar e enquadrar questões sobre conhecimento, o design se torna um método intelectual. O campo do design vem explorando com sucesso a tecnologia 
para a produção cultural, seja como tecnologias de produtos úteis ou por meio da formação do imaginário cultural. Como as Humanidades Digitais moldam e interpretam esse imaginário, seu envolvimento com o design como um método de pensamento através da prática é indispensável. (BURDICK, [et al.]. 2012 p. 13).

Diante do exposto, a proposta de disponibilizar um projeto que envolva o tema Design e Tecnologia em forma de livros para a reflexão sobre características e possibilidades de interrelação do design, da educação, da comunicação, de serviços e da tecnologia no contexto complexo do ambiente das mídias se faz oportuna, pois de acordo com Santaella (2013):

A expressão "ecologia das mídias" tornou-se corrente desde que passamos a viver em uma sociedade mediatizada e midiatizada. As duas palavras se distinguem. Mediatizada vem de mediação, um conceito epistemológico que se traduz por signos de todas as naturezas - verbais, visuais, sonoros e todas as suas misturas - que se encarnam, circulam e são difundidos pela midiatização. (SANTAELLA, 2013 p. 13)

Ainda segundo a autora, para viver na atual sociedade extremamente complexa faz-se necessário ser capaz de distinguir entre diferentes linguagens e mídias, suas naturezas comunicativas específicas e suas injunções político-sociais. A partir desse entendimento, é possível ter condições para desenvolver a capacidade de criticar e levantar questões acerca de tudo que lemos, vemos e escutamos, ou seja, tornar-se críticos das informações recebidas.

Para Burdick et al. (2012), livros impressos e estudos humanísticas têm uma história compartilhada. Durante séculos, os humanistas trabalharam com formatos - a página impressa, o códice encadernado - que permanecem consistentes. Mas a comunicação em ambientes digitais exigiu a invenção de novos formulários, ferramentas e esquemas. A falta de convenções e a oportunidade de imaginar formatos com affordances muito diferentes do que a impressão não apenas, trouxeram reconhecimento da transformação da construção sociocultural e implicações cognitivas diversas dos formatos impressos, mas também destacaram o papel do design na comunicação. (BURDICK, [et al.]. 2012 p.10).

Ainda segundo os autores, o design com "D", caixa alta, abrange desde o "Design Thinking" até as "Ciências do Design", que incluem domínios acadêmicos, especializações, como engenharia e interação humano-computador. Segundo os autores, os projetos de Humanidades Digitais envolvem mais especificamente designers de comunicação visual que estão preocupados com a representação simbólica da linguagem, expressão gráfica de conceitos e questões de estilo e identidade. Incluem também, os designers de interação e experiência do usuário. (BURDICK, [et al.]. 2012 p. 1).

Nas palavras de Moles (1989), o Design procura transformar visibilidade em legibilidade, ou seja, de operações da mente que organizam coisas sob a forma de signos (volumes, superfícies, ângulos, contornos), em um todo inteligível de modo a preparar uma estratégia para a ação. $\mathrm{E}$, ao proceder assim - ao assumir a responsabilidade pelo aspecto simbólico do mundo, sendo este influente em opiniões e ações - o design gráfico (que projeta o ambiente circundante) carrega em si uma expressividade social (MOLES, 1989, p.124).

O Design é um processo ativo que influencia a sociedade criando sua cultura material. Segundo esta ótica, Meurer (1997) diz que o mundo em que vivemos é mais que a matéria - que 
se há solidificado como forma - e que se deteve no tempo. Sua forma está definida mediante a atividade, e a ação é o seu centro. Se o Design é concebido orientado em direção à ação, entendida como interação ativa e mudança criadora, ele não focará somente o objeto como forma. Ao contrário, os designers irão preocupar pelo desenvolvimento de modelos de processos interativos, nos quais os objetos desempenham um papel central indiscutível como meio para a ação. Segundo esta visão, o Design se relaciona com a totalidade do espectro concreto e intelectual da interação humana, da interação entre as pessoas, dos produtos, e com o mundo em que habitamos.

Vivemos uma época em que a Internet, assim como os diversos equipamentos e tecnologias disponíveis para se conectar a ela, possibilitou a construção de um novo paradigma de geração de conhecimento e acesso à informação. Moura (2003) enfatiza esta ideia ao constatar que, apesar da agilidade na mudança de sistemas e processos, podemos perceber que as tecnologias digitais exteriorizaram e impulsionaram quatro qualidades do ser humano: a curiosidade, a criatividade, a cooperação e a vivência do lúdico. Sendo a interatividade apontada como uma das melhores aberturas para estas questões e para o pensamento criador (MOURA, 2003, p. 206).

É importante dizer que a relação com o saber modificou-se e possibilitou uma ação diferenciada do usuário por meio das tecnologias de informação e comunicação. Para Silva (2012):

\begin{abstract}
A disposição interativa permite ao usuário ser ator e autor, fazendo da comunicação não apenas o trabalho da emissão, mas co-criação da própria mensagem e da comunicação. Permite a participação entendida como troca de ações, controle sobre acontecimentos e modificação de conteúdos. O usuário pode ouvir ver, ler, gravar, voltar, ir adiante, selecionar, tratar e enviar qualquer tipo de mensagem para qualquer lugar. Em suma, a interatividade permite ultrapassar a condição de espectador passivo para a condição de sujeito operativo (SILVA, 2012, s.p.).
\end{abstract}

A elaboração de um livro digital online permitirá aos leitores, desenvolvedores de projetos de Humanidades Digitais, dentre outros obterem informações sobre os processos e ferramentas disponíveis para a criação de ambientes hipermidiáticos e transmidiáticos. Esta iniciativa surge como uma oportunidade de inserir o estudo do Design a esse novo modelo de informação: hipertextual e multimidiático.

Apoia esta ideia Jenkins (2009), quando aponta a necessidade de se refletir sobre o tema desta pesquisa. Para o autor não temos ainda critérios estéticos muito bons para avaliar obras que se desenvolvem através de múltiplas mídias. Houve muito poucas histórias transmídia para os produtores de mídia agirem com alguma certeza sobre quais seriam os melhores usos desse novo modo de narrativa, ou para críticos e consumidores saberem como falar, com conhecimento de causa, sobre o que funciona ou não nessas franquias. (JENKINS, 2009, p.139)

Isso revela a fragilidade de uma conduta carente de critérios no desenvolvimento de linguagens de hipermídia e de transmídia. Dessa forma, segundo Portugal (2013) torna-se imprescindível, para o campo do Design e áreas afins refletir sobre as articulações entre esses múltiplos meios disponibilizados por intermédio de texto (incluindo números, tabelas etc.), de imagem (fotografia, ícone, imagem 3D etc.), de vídeo (imagem em movimento), de som (música, voz humana, som com efeito especial etc.), de animação (desenho animado, gifs etc.) e de gráfico (infográficos), de modo a dar significado ao conteúdo que se pretende disponibilizar, visando criar informações de forma dinâmica, atraente e significativa. 
Nesta mesma linha de pensamento, Drucker (2014) problematiza que, podemos argumentar que o conhecimento visual pode ser considerado codificado desde que as formas gráficas como, triângulos, quadrados, círculos dentre outros são descritos em desenhos e textos. Estes tratados não são manuais de design ou desenho, são expressões gráficas, matemáticas, lógicas, de conhecimento de uma forma visual e verbal sistemática. Em contraste com tais tratados matemáticos, séculos depois, as obras que compõem a "linguagem" da comunicação gráfica são mais retóricas do que lógicas. Suas características podem ser descritas em termos de princípios visuais relacionados à visão, percepção, cognição, convenções culturais e normas. Todas essas investigações de formas visuais como uma expressão sistemática de conhecimento contribuem para a busca de uma "linguagem" de gráficos. (DRUCKER, 2014, p.19).

Nas palavras de Bonsiepe (2011), os conhecimentos considerados como experiências acumuladas devem ser comunicados e compartilhados, sendo que a apresentação da informação/conhecimento deveria ser uma tarefa central do design.

Assim, se faz oportuno pesquisar sobre design tendo como foco as diferentes linguagens de mídia de modo interdisciplinar. Nas palavras de Bomfim, é preciso entender: " $a$ interdisciplinaridade, como condição inerente e essencial à prática do design". (BOMFIM, 1997, p. 30)

\section{Sobre o projeto Design * Tecnologia}

O presente projeto pretende disponibilizar uma série de livros, como foi dito anteriormente, porém os conteúdos dos novos livros seguirão a mesma estratégia de produção do primeiro livro digital: Design, Educação e Tecnologia. A apresentação da informação é feita de maneira multilinear, como hipertexto, e estruturada em nós semânticos ligados entre si (em rede), que oferecem alternativas para a navegação. Em 2017, o livro digital Design, Educação e Tecnologia passou por revisão e redesign para, em sua 2 o edição, se tornar o primeiro livro a integrar a série de Design * Tecnologia.

Figura 1 - Captura de tela exibindo Home page doprojeto Design* Tecnologia

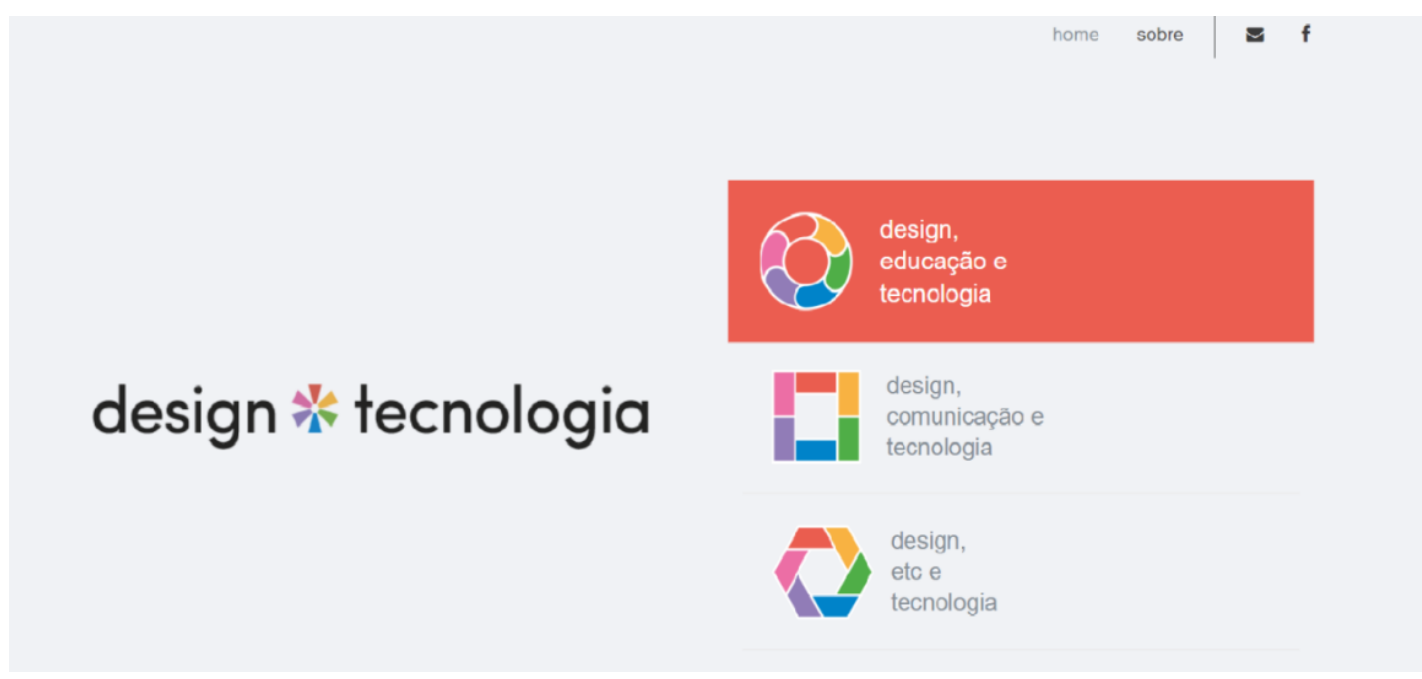

Fonte: Arquivo do autor (2018) 
O conteúdo do novo livro, objeto deste estudo, se dividirá em quatro módulos e cada módulo abordará um dos seguintes temas: Comunicação, Narrativas digitais, Humanidades Digitais e Hipermídia/Transmídia. Os textos de cada módulo serão apoiados por exemplos, referências bibliográficas e por uma seção denominada "Saiba mais". Os textos trarão a fundamentação teórica de cada módulo; os exemplos serão selecionados para ilustrar o texto e exemplificar o conteúdo do mesmo, por meio de imagens, gráficos, vídeos, animações, etc.; as referências bibliográficas serão divididas por tema para facilitar a pesquisa do leitor; e o "Saiba mais" apresentará informações complementares aos textos principais, oferecendo uma seleção de livros, sites, aplicativos, jogos e/ou filmes que possibilitem ao usuário do livro aprofundar-se em cada tema em particular.

Como dito anteriormente, cada módulo contemplará um tema. Os temas, no entanto, deverão se dividir em subtemas, para melhor organizar o conteúdo, tornando a leitura mais fácil e objetiva. Dessa forma, cada subtema contará com um texto teórico e seus respectivos exemplos. As referências bibliográficas e o "Saiba mais" contemplarão todos os subtemas, representando, assim, o tema como um todo.

O quadro a seguir, apresenta os principais temas do livro Design, Comunicação e Tecnologia. A figura 2 apresenta o resumo do projeto Design* Tecnologia publicado no livro de resumos intitulado. Intentions: Conversations, Experiences and Knowledg, que reúne alguns dos projetos que foram iniciados em 2017 na School of Communication da Royal College of Art.

Arquitetura da informação do livro digital

\begin{tabular}{|c|c|c|c|}
\hline \multicolumn{4}{|c|}{ DESIGN, COMUNICAÇÃO E TECNOLOGIA } \\
\hline Comunicação & Narrativa digital & $\begin{array}{l}\text { Hipermídia/ } \\
\text { Transmídia }\end{array}$ & $\begin{array}{l}\text { Humanidades } \\
\text { Digitais }\end{array}$ \\
\hline \multirow{2}{*}{ Subtemas } & \multicolumn{3}{|c|}{ Fundamentação teórica } \\
\hline & \multicolumn{3}{|c|}{$\begin{array}{l}\text { Exemplos de apoio à teoria (imagens, gráficos, vídeos, } \\
\text { animações) }\end{array}$} \\
\hline \multicolumn{4}{|c|}{ Referências bibliográficas } \\
\hline Saiba Mais: Seleç & $\begin{array}{l}\text { erências externas } \\
\text { jogos, filme }\end{array}$ & $\begin{array}{l}\text { re o tema (livrc } \\
\text { c.) }\end{array}$ & es, aplicativos, \\
\hline
\end{tabular}


Figura 2 - Resumo do projeto publicado

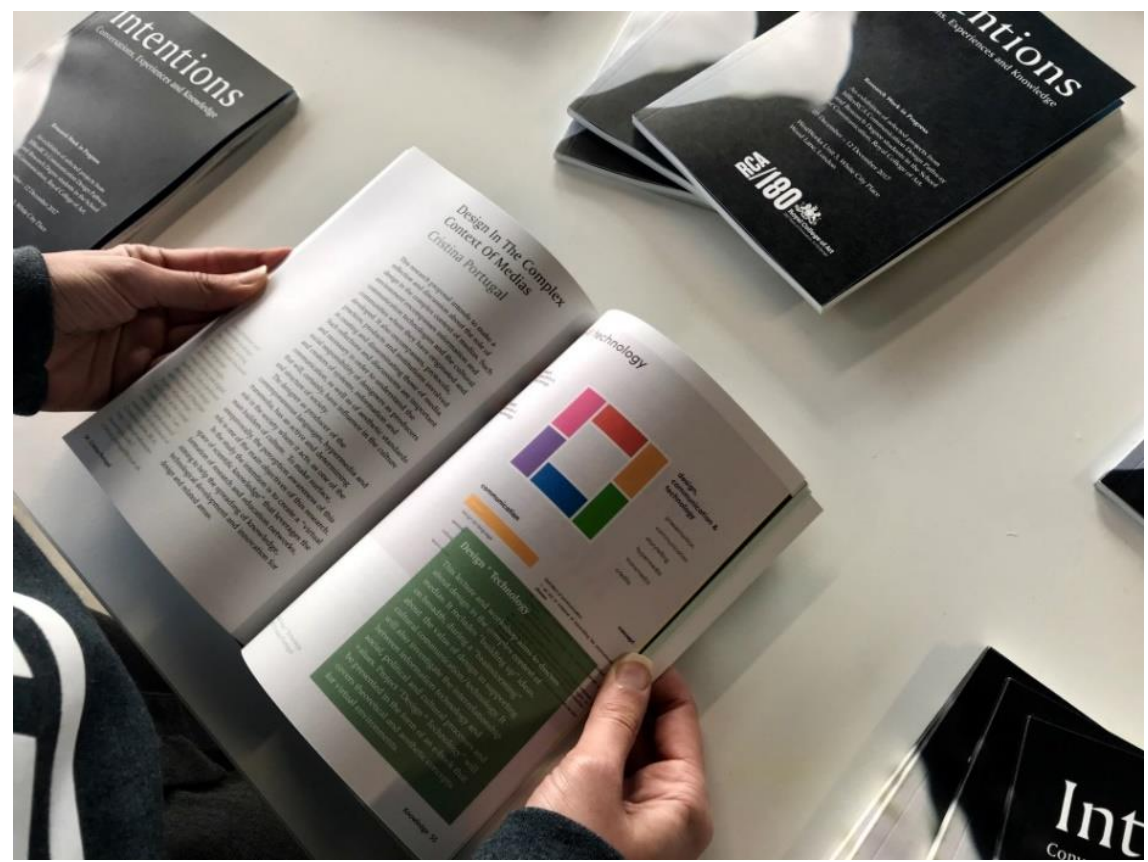

Fonte: PORTUGAL, 2017 p.54

Portanto, este projeto justifica-se, uma vez que os sistemas de informação estão hoje inseridos em um ambiente de permanente desafio, que requer atualização e desenvolvimento de novas formas de apresentação, para além das tradicionais - associando gráficos, tipografia, movimento, som e interatividade e tornando-se compreensível e utilizável pelas pessoas. Nesse sentido, torna-se fundamental buscar novas formas de visualização da informação contemplando as possibilidades das tecnologias digitais considerando que as relações sociais são mediadas por uma rede plural de linguagens.

Enfatiza Santaella (2001), a problemática sobre a questão do estudo das diferentes linguagens possibilitadas pelas mídias.

É tal a distração que a aparente dominância da língua provoca em nos que, na maior parte das vezes, não chegamos a tomar consciência de que nosso estar no mundo, como indivíduos sociais que somos, é mediado por uma rede intrincada e plural de linguagem, isto é, que nos comunicamos também através da leitura e/ou produção de formas, volumes, massas, interações de forças, movimentos que somos também leitores e/ou produtores de dimensões e direções de linhas, traços, cores. Enfm. Também nos comunicamos e nos orientamos através de imagens, gráficos, sinais, setas, números, luzes. Através de objetos, sons, musicas, gestos, expressões, cheiro e tato, através do olhar, do sentir e do apalpar. Somos uma espécie animal tão complexa quantosão complexas e plurais as linguagens que nos constituem como seres simbólicos, isto é, seres de linguagem (SANTAELLA, 2001 p. 10),

Diante do exposto Drucker (2014) alerta que, a onipresença dos formatos gráficos nos ambientes digitais requer uma nova compreensão crítica das maneiras como lemos e processamos 
informações visuais. Aprender a ler o argumento de produção de significado. A interface gráfica de usuário (GUI) é o formato dominante de telas em todas as formas e tamanhos. Nenhuma única inovação transformou a comunicação radicalmente no último meio século como a GUI. Num sentido muito real e prático, realizamos a maior parte de nossas tarefas diárias sejam pessoais ou profissionais por meio de interfaces. Torna-se imprescindível entender como a interface estrutura nossa relação com o conhecimento e nosso comportamento social.

Neste sentido, Schumacher (2011) constata que ambientes e artefatos construídos podem funcionar como interfaces de comunicação social. O que todas as disciplinas de design e seus produtos compartilham é a função social. Assinala que toda sociedade precisa utilizar relações espaciais articuladas para enquadrar, ordenar e estabilizar a comunicação social. Portanto tornase primordial refletir sobre linguagem midiática considerando o Design enquanto sistema de comunicação. Estas ideias serão contempladas no projeto Design * Tecnologia, objeto deste estudo.

\section{Conclusão}

Com a avalanche de mídias, aplicativos e sistemas com os quais interagimos cotidianamente, as transformações tecnológicas e suas consequências (sociais, éticas, culturais, educacionais, ambientais, dentre outras) se processam em ritmo célere, produzindo novas formas de interação, aquisição de conhecimentos e experiências.

Diante deste fato, buscar novas formas de conceber e produzir design se torna fundamental, como afirma Manzini (2004) sobre a necessidade de pensar "o design em um mundo fluido", no qual produtos, serviços e informações se combinam e geram modos de projetar, produzir, consumir e utilizar de forma inédita, que resultam da articulação de uma multiplicidade de atores. $\mathrm{O}$ autor diz que para atuar neste contexto, os designers "têm que mudar seu perfil profissional, convertendo-se em operadores que atuam dentro de uma rede, assumindo o papel de provedores do processo de inovação". Ao considerar a possibilidade de soluções sustentáveis, a atividade de design que impulsiona o processo de inovação deve ser facilitada pelos designers, em vez de ser diretamente realizada por eles. (MANZINI, 2004, p. 17 - 20). Manzini intensifica suas ideias afirmando que o designer, a partir de sua criatividade e de suas habilidades de comunicação, pode contribuir para promover um alto grau de participação social ativa. Essas ideias vêm ao encontro de pensar o Design para projetos em "Humanidades Digitais"..

Geralmente, as frágeis iniciativas de aplicação das linguagens midiáticas como algo para possibilitar o acesso e disseminação da informação não são desenvolvidas em todo seu potencial em projetos de "Humanidades Digitais", considerando que por meio da tecnologia da informação e comunicação tornam possíveis modelos de mediação diferentes dos pensados para sistemas analógicos. Devido ainda, a carência de estudos e da aplicação de métodos e técnicas de design às praticas em "Humanidades Digitais" perde-se a oportunidade de criar um novo tipo de experiência e relação entre os usuários, os produtos e as instituições.

O Design, como produtor das linguagens contemporâneas - entre elas a hipermídia e a transmídia -, tem um papel ativo e determinante na sociedade onde atua, como um dos principais edificadores da cultura. Fazer aflorar, de forma inequívoca, a percepção e a conscientização deste papel do design é um dos objetivos principais deste projeto de pesquisa. 


\section{Agradecimento}

CAPES Foundation, Ministry of Education of Brazil, Brasilia - DF, Zip Code 70.040-020. "Bolsista da CAPES - Proc. N. 88881.119789/2016-01". Supervisora da pesquisa Profa. Dra. Teal Triggs da School of Communication - RCA. Mariana Corrêa e Luciana Leme membros desta pesquisa.

\section{Referências}

BOMFIM, G. A. "Fundamentos de uma teoria transdisciplinar do design: morfologia dos objetos de uso e sistemas de comunicação". In: Estudos em Design, N.2, V.5, RJ, AEND-BR, 1997, P.27-41.

BONSIEPE, G. Design, Cultura e Sociedade. São Paulo: Edgar Blucher, 2011.

BURDICK, A., [et al.]. Digital_humanities. Massachusetts: MIT Press, 2012.

DACOS, M. Manifesto das Humanidades Digitais. Disponível em: https://tcp.hypotheses.org/497. (2011). Acesso 22 mar. 2018.

DRUCKER, J. Graphesis\; Visual Forms of Knowledge Production. Cambrfge, MA: Havatd University Press. 2014.

CUDDON, J. A. A Dictionary of Literary Terms and Literary Theory. WileyBlackwell, British Library, 2013.

HUMANIDADES DIGITAIS: Grupo de Pesquisas: Universidade de São Paulo. Disponível em: https://humanidadesdigitais.org/o-que-sao-humanidades-digitais/b. Acesso 25 mar. 2018.

JENKINS, H. Cultura da convergência. São Paulo: ALEPH, 2009.

MCLUHAN, M.; MCLUHAN, E. Laws of Media: the New Science [LoM]. Toronto: University of Toronto Press, 1988.

MANZINI, E. El diseño como herramienta para la sostenabilidad medioambiental y social. In: Macdonaldo, s. (org.) Design issues in Europe today. Barcelona: BEDA, 2004.

MEURER, B. User-Centred Graphic Design: In FRASCARA, Jorge, MEURER, Bernd, TOORN, Jan van, WINCKLER, Dietmar. Mass Communication And Social Change. CRC Pres, 1997.

MOLES, A. A. The Legibility of the World: A Project of Graphic Design. MARGOLIN, Victor (ed.). Design discourse: history, theory, criticism. Chicago: The Universityof Chicago Press, 1998, p.119129.

MOURA M. Design de hipermídia: novo campo e ação no ensino, na aprendizagem e na formação profissional. Disponível em: http://www.designdehipermidia.com.br/dh_mm/2/2.htm. Acesso 05 jan. 2018.

PORTUGAL, C. Design, educação e tecnologia: Rio de Janeiro: Rio Books, 2013.

Design in the complex context of medias. In: TRIGGS, T. SIMMONS, T., CANDELA, E. Intentions: Conversations, Experiences and Knowledge. LONDON: Royal College of Art, 2017.

Design, educação e tecnologia (online): Rio de Janeiro: Rio Books, 2013. Disponível em: 
www.design-educacao-tecnologia.com. Acesso 25 mar. 2018.

Hypermedia E-book as a Pedagogical Tool in a Graduation Course. International journal of modern education and computer science (IJMECS), v. 6, p. 8-14, 2014.

SANTAELLA, L. Navegar no ciberespaço: o perfil cognitivo do leitor imersivo. São Paulo: Paulus, 2004 3a. edição, 2009.

SCHUMACHER, P. Design is Communication. In: Kathryn Bloom Hiesinger, Zaha Hadid: Form in Motion. Philadelphia Museum of Art in association with Yale University Press, New Haven, 2011.

SAYERS, J. Making Things and Drawing Boundaries. Experiments in the Digital Humanities. Minissota: University f Minissota Press. 2018.

TRIGGS, T.; SIMMONS, T.; CANDELA, E. Intentions: Conversations, Experiences and Knowledge. LONDON: Royal College of Art, 2017. 